\title{
Modeling for Development of Simulation Tool: Impact of TCSC on Apparent Impedance Seen by Distance Relay
}

\author{
Ngo Minh Khoa \\ Faculty of Engineering and Technology \\ Quy Nhon University \\ Quy Nhon, Binh Dinh, Vietnam \\ ngominhkhoa@qnu.edu.vn
}

\author{
Doan Duc Tung \\ Faculty of Engineering and Technology \\ Quy Nhon University \\ Quy Nhon, Binh Dinh, Vietnam \\ doanductung@qnu.edu.vn
}

\begin{abstract}
The impact of thyristor controlled series capacitor (TCSC) on distance protection relays in transmission lines is analyzed in this paper. Voltage and current data are measured and collected at the relay locations to calculate the apparent impedance seen by distance protection relays in the different operating modes of the TCSC connected to the line. Short-circuit faults which occur at different locations on the power transmission line are considered in order to locate the fault for the purpose of evaluating the impact of TCSC on the distance protection relay. Matlab/Simulink simulation software is used to model the power transmission line with two sources at the two ends. Voltage source, transmission line, TCSC, voltage and current measurement, and discrete Fourier transform (DFT) blocks are integrated into the model. Simulation results show the impact of TCSC on the distance protection relay and determine the apparent impedance and fault location in the line.
\end{abstract}

Keywords-apparent impedance; distance relay; firing angle; TCSC; transmission line.

\section{INTRODUCTION}

Flexible alternating current transmission systems (FACTS) based on power electronics have been developed to improve the performance of weak alternating current (AC) systems and to make long distance AC transmission systems feasible [1, 2]. Series compensation with TCSC has various applications in power system control such as readjustment of power flow, transient stability control, power oscillation damping control and sub-synchronous resonance mitigation because of its continuously varying reactance capability $[3,4]$. The presence of a TCSC in fault loop affects both steady state and transient components of the voltage and current. Moreover, variable capacitance or inductance in TCSC can lead to subsynchronous oscillations under overreaching distance protection and has an influence on the apparent impedance seen by distance protection relays $[5,6]$. Hence, a model for the development of a simulation tool that analyzes the impact of $\mathrm{TCSC}$ on distance protection relay in power transmission lines is necessary.

Authors in [7] proposed the fault direction estimation technique for a transmission line with a TCSC. A compensated line imposed problems to directional relaying schemes due to reactance modulation, current, and voltage inversion issues and TCSC-control action in order to estimate the direction of fault for a line with TCSC. Authors in [8] considered TCSC as a dynamical device which had the response to disturbances based on its own control strategy. It concluded that not only TCSC affects the protection of its line, but also the protection of adjacent lines would experience problems. In [9], the impact of TCSC on the performance of conventional communication aided distance protection schemes was analyzed. Authors also proposed new schemes for mitigating the impact of TCSC which used the information available at the substation to inhibit relay malfunctions. Authors in [10] presented a new protective scheme for transmission lines compensated by TCSC. The scheme employed the averages of voltage and current, a new criterion was introduced to discriminate between forward and reverse faults. Authors in [11] proposed a new high speed Mho distance protection scheme for single line to ground faults in TCSC line in which fault voltage and current at relay point and firing angle from the TCSC substation were taken as the input for the Mho relay.

The objective of this paper is to model and analyze the impact of TCSC on the performance of based protection relays under normal operation and different single-phase to ground fault conditions. Therefore, to address the aforementioned issues, this paper develops a simple power system model including a transmission line with a TCSC and single-phase to ground faults are investigated. According to the simulation results, the apparent impedance seen is calculated to analyze the impact of TCSC to distance protection relay on the line.

\section{OPERATION PRINCIPLES OF TCSC}

TCSC is used in power systems to dynamically control the reactance of a transmission line in order to provide sufficient load compensation [12]. The benefits of TCSC are seen in its ability to control the amount of compensation of a transmission line, and in its ability to operate in different modes. These traits are very desirable since loads are constantly changing and cannot always be predicted. TCSC designs operate in the same way as fixed series compensation, but provide variable control 
of the reactance absorbed by the capacitor device. The control scheme of a TCSC [13] is shown in Figure 1.

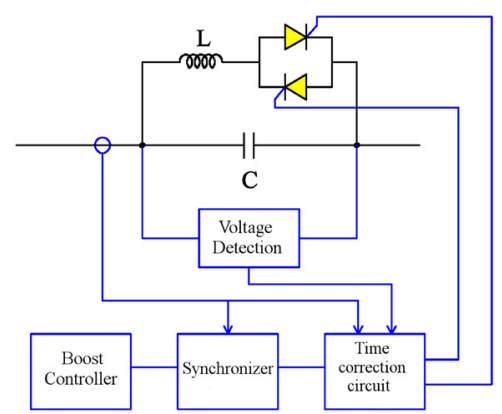

Fig. 1. Control scheme of TCSC.

Change of impedance of TCSC is achieved by changing the thyristor controlled inductive reactance of inductors connected in paralleled to the capacitor. The magnitude of inductive reactance is determined by the firing angle $\alpha$, which can also be controlled continuously by the flowing amplitude of current reactor from maximum value to zero. Firing angle switching thyristors can change inductive reactance controlled choke from a minimum value to, theoretically, infinite value. The TCSC equivalent reactance is as a function of its capacitive and inductive reactance parameters, and the firing angle $[14,15]$ :

$$
\begin{aligned}
& X_{T C S C}(\alpha)=-X_{C}+C_{1}\{2(\pi-\alpha)+\sin [2(\pi-\alpha)]\} \\
& -C_{2} \cos ^{2}(\pi-\alpha)\{\varpi \tan [\varpi(\pi-\alpha)]-\tan (\pi-\alpha)\}
\end{aligned}
$$

where:

$$
\begin{aligned}
& C_{1}=\frac{X_{C}+X_{L C}}{\pi} \\
& C_{2}=\frac{4 X_{L C}^{2}}{\pi X_{L}} \\
& X_{L C}=\frac{X_{C} X_{L}}{X_{C}-X_{L}} \\
& \varpi=\sqrt{\frac{X_{C}}{X_{L}}}
\end{aligned}
$$

An appropriate value for capacitance and inductance of a TCSC device is based on the net reactance of the transmission line and expected power demands in future. Selection of capacitance and inductance values of TCSC can be summarized by the following steps:

- Step 1: Select the degree of compensation $(K)$.

- Step 2: Calculate capacitive reactance $\left(X_{C}\right)$ and capacitance value of TCSC from (6) and (7), respectively.

$$
X_{C}=K \times X_{T L}
$$

where $X_{T L}$ is the total reactance of the transmission line.
The capacitance value of TCSC is given by (7):

$$
C=\frac{1}{2 \pi f X_{C}}
$$

where $f$ is the fundamental frequency.

- Step 3: The choice of inductance value depends on the length of operating area required for inductive and capacitive region. It is decided by the factor $\varpi$, given in (5) by shifting the position of resonance region. Finally, inductance value of TCSC is given by (8):

$$
L=\frac{X_{L}}{2 \pi f}
$$

The TCSC capacitive and inductive reactance values should be chosen carefully in order to ensure that just one resonant point is present in the range of $90^{\circ}$ to $180^{\circ}$. Figure 2 shows the TCSC fundamental frequency reactance, as a function of the firing angle.

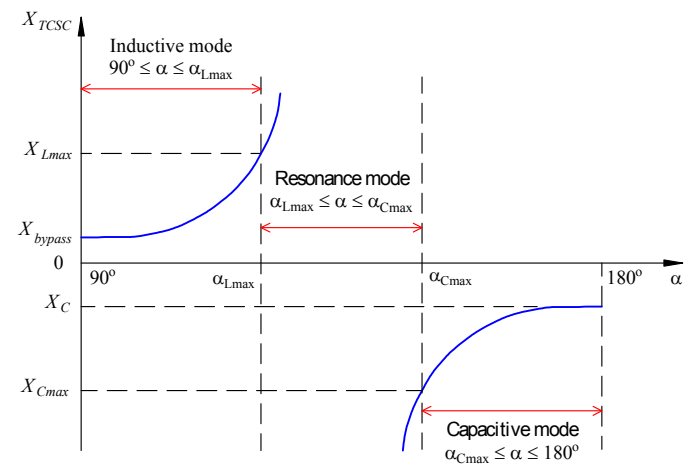

Fig. 2. TCSC fundamental frequency reactance characteristic curve

TCSC operates in different modes depending on when the thyristors for the inductive branch are triggered. The modes of operation are [16]:

- Blocking mode: Thyristor valve is always off, opening inductive branch, and effectively causing the TCSC to operate as fixed series compensation.

- Bypass mode: Thyristor valve is always on, causing TCSC to operate as capacitor and inductor in parallel, reducing the current through TCSC.

- Capacitive boost mode: Forward voltage thyristor valve is triggered slightly before capacitor voltage crosses zero to allow current to flow through the inductive branch, adding to capacitive current. This effectively increases the observed capacitance of the TCSC without requiring a larger capacitor within the TCSC.

The presence of TCSC systems with its reactor $\left(X_{T C S C}\right)$ has a direct influence on the total impedance of the protected line $\left(Z_{i j}\right)$, especially on the reactance $X_{i j}$ and no influence on the resistance $R_{i j}$. The new setting zones (zone 1, zone 2, and zone 3) for a protected transmission line with TCSC connected at midline are: 


$$
\begin{aligned}
& Z_{1}=0.8 \times\left[R_{i j}+j X_{i j}+j X_{T C S C}(\alpha)\right] \\
& Z_{2}=\left[R_{i j}+j X_{i j}+j X_{T C S C}(\alpha)\right]+0.2 \times\left(R_{j k}+j X_{j k}\right) \\
& Z_{3}=\left[R_{i j}+j X_{i j}+j X_{T C S C}(\alpha)\right]+1.2 \times\left(R_{j k}+j X_{j k}\right)
\end{aligned}
$$

where $Z_{1}, Z_{2}, Z_{3}$ are setting zones 1,2 and 3, respectively, $R_{i j}$, $X_{i j}$ are resistance and reactance of the protected line $i j$, respectively and $R_{j k}, X_{j k}$ are resistance and reactance of the line $j k$ which follows the line $i j$, respectively.

\section{MODELING OF IMPACT OF TCSC ON DISTANCE RELAY}

\section{A. Studied System Description}

A 3-phase, $500 \mathrm{kV}, 400 \mathrm{~km}$ long transmission line, as shown in Figure 3, is investigated in this section. The transmission line has a TCSC at the sending end of the line. The transmission line and TCSC parameters are given in the Appendix. Inductance and capacitance of TCSC are determined by using the previous equations and they are also given in the Appendix. By changing the firing angle from $150^{\circ}$ to $180^{\circ}$, TCSC capacitive reactance calculated using (1) is shown by negative values in Figure 4. TCSC provides $20 \%$ compensation at $180^{\circ}$ (minimum), 69.53\% compensation at $150^{\circ}$ (maximum) firing angle.

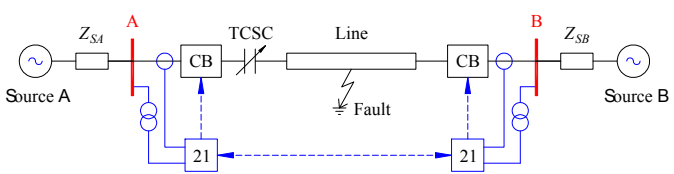

Fig. 3. The transmission line with TCSC.

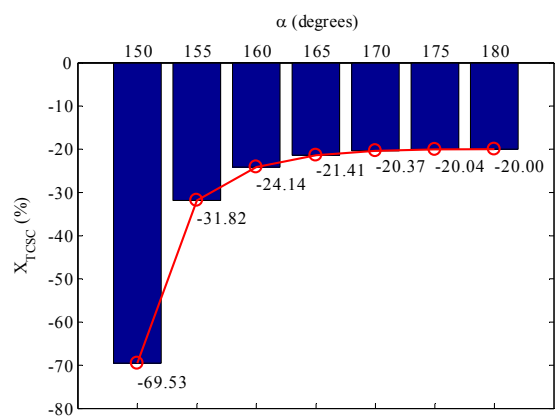

Fig. 4. TCSC capacitive reactance based on the firing angle.

The studied power system has been simulated using Matlab/Simulink software. Voltage and current data are collected at a sampling frequency of $1.0 \mathrm{kHz}$. Samples of voltage and current signals are used to determine the phasors which are used to calculate the apparent impedance seen by the relay and to determine a fault in distance relay's zone of protection. DFT is a tool for the phasor estimation of voltage and current signals. The algorithm for single-phase to ground (Ph-G) fault is shown in Figure 5. The algorithm can be explained by the following steps:

- Step 1: Set system conditions including parameters of the sources and transmission line.
- Step 2: Set single-phase to ground fault in the line.

- Step 3: Acquire voltage and current from voltage transformers VTs and current transformer CTs.

- Step 4: Computation of voltage $V_{p h}$ and current $I_{p h}$ phasor components using DFT.

- Step 5: Computation of the zero-sequence current phasor component $I_{0}$.

- Step 6: Computation of the apparent impedance seen by the distance relay as (12).

$$
Z=\frac{V_{p h}}{I_{p h}+k I_{0}}
$$

where $V_{p h}, I_{p h}$ are the faulted phase voltage and current, respectively, $I_{0}$ is the zero-sequence current component and $k=\left(z_{0}-z_{1}\right) / z_{1} \cdot z_{0}, z_{1}$ are zero-sequence and positive-sequence line impedances per kilometer.

- Step 7: Update the fault position and resistance and return to Step 2.

- Step 8: Finally, determine resistance and reactance $R, X$.

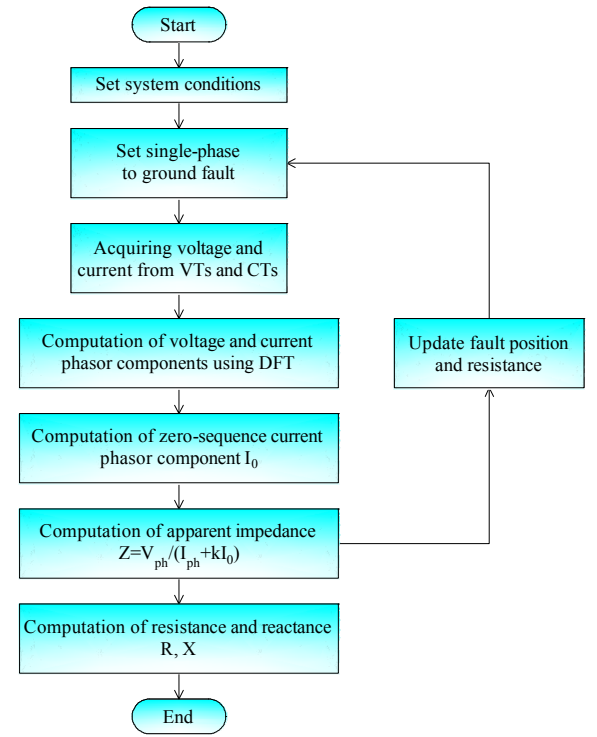

Fig. 5. The flow diagram for tripping characteristics.

\section{B. Simulation Results and Discussion}

In order to verify the correctness of the modeling of impact of TCSC on the apparent impedance seen by distance protection relay, the system described in the previous section was modeled in Matlab/Simulink as shown in Figure 6. In this model, the three-phase source blocks, Source A and Source B, implement a balanced three-phase voltage source with internal $\mathrm{R}-\mathrm{L}$ impedance. The two voltage sources are connected in $\mathrm{Y}$ with a grounded-neutral connection. The transmission line block implements a balanced three-phase transmission line model with parameters lumped in a PI section. The line parameters $\mathrm{R}, \mathrm{L}$, and $\mathrm{C}$ are specified as positive- and zero- 
sequence parameters that take into account the inductive and capacitive couplings between the three phase conductors, as well as the ground parameters. The line is divided in two segments (segment 1 and segment 2) because the Ph-G fault is located at mid-point of the line. The fault location can be changed by setting the length of the two segments. It is assumed that the fault location is at different positions on the line and it occurs at $0.4 \mathrm{~s}$ in total simulation time of 2 seconds. Moreover, the fault resistance is also changed from $0 \Omega$ to $50 \Omega$ in order to evaluate the impact of TCSC on the relay A. TCSC is modeled by using a series RLC branch block which can change its reactance parameters according to the equations presented in Section II. The firing angle is set to change the reactance of TCSC and simulate the changing apparent impedance seen by distance relay. However, the firing angles of TCSC, $180^{\circ}, 155^{\circ}$, and $150^{\circ}$ are used to measure the impact of TCSC on distance relay tripping characteristics in this study.

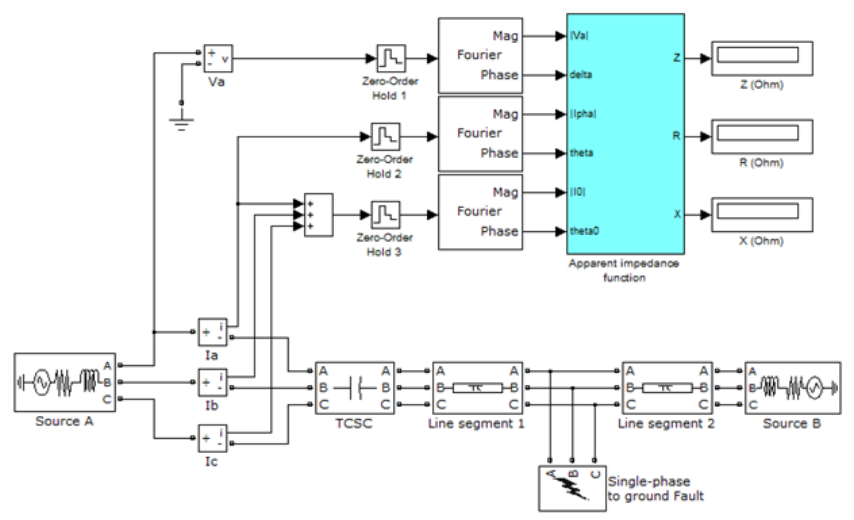

Fig. 6. Simulated system

A Ph-G fault beginning at 0.4 seconds is established at the $100 \%$ of the line length and the fault resistance is set by zero $\left(R_{f}=0 \Omega\right)$. Four hypotheses (without TCSC in the line, with TCSC at the firing angle of $180^{\circ}, 155^{\circ}$, and $180^{\circ}$ ) are simulated in the study. With total time of 2 seconds, the simulation results of this case, including the phase current, phase voltage, zerosequence current, and apparent impedance seen by the relay A are shown in Figure 7. Meanwhile, the voltage and current measurement data are acquired by VTs and CTs and are sampled by a specific period. The magnitude of faulted phase current at the relay A is shown in Figure 7(a). At the beginning time of the fault ( 0.4 seconds), there is a transient period in the current magnitudes and then they are stable at their new steady state. Because of the firing angle, the faulted phase current magnitudes are at different values as shown in Figure 7(a). Among these values, the current magnitude in the case with TCSC at the firing angle of $150^{\circ}$ is the highest one and the current magnitude in the case without TCSC is the lowest one because the firing angle changes the reactance of TCSC. The magnitude of faulted phase voltage at the relay A is shown in Figure 7(b). After the fault starts, the phase voltage magnitude decreases to new value. However, the voltage magnitude in the case with TCSC at the firing angle of $150^{\circ}$ is the lowest one and the voltage magnitude in the case without TCSC is the highest one. The zero-sequence current is shown in Figure 7(c).
Before the fault occurs, it is zero because the system is almost balanced. Ph-G fault is applied at 0.4 seconds and the zerosequence current increases. The component is also used to calculate the apparent impedance seen by the relay A which is shown in Figure 7(d). The apparent impedance seen by the relay A depends on the firing angle of TCSC. The impedance in the case with the presence of TCSC at the firing angle of $150^{\circ}$ is the lowest one and the impedance in the case without TCSC is the highest one.

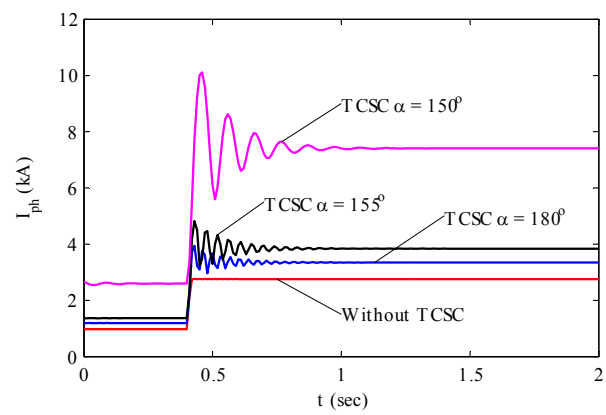

(a) Phase current

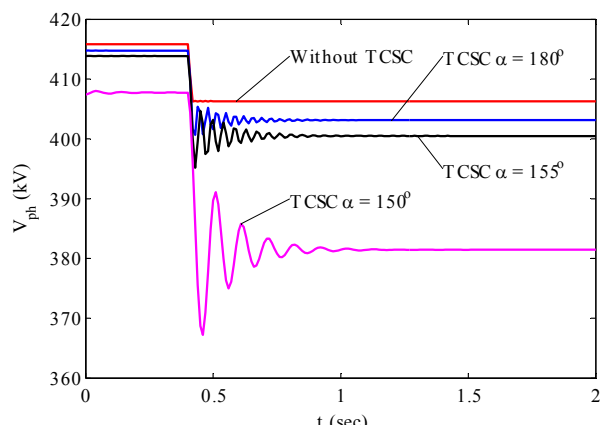

(b) Phase voltage

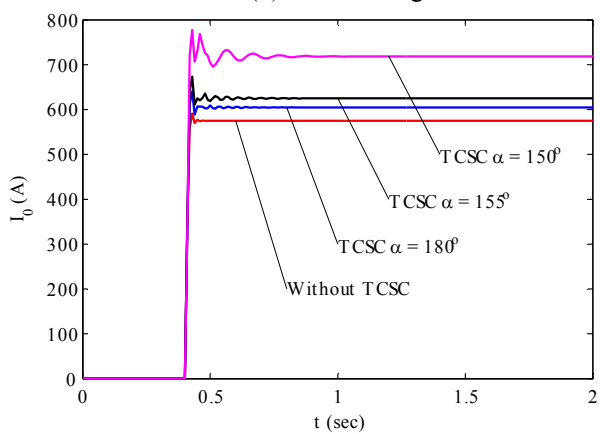

(c) Zero-sequence current

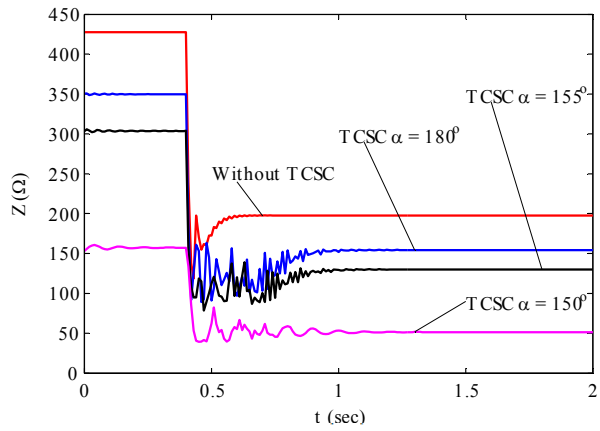

(d) Apparent impedance

Fig. 7. Apparent impedance for solid fault at $100 \%$ line length. 
In order to show the changing apparent impedance seen by the relay A according to the fault location, the fault is assumed to occur at different locations on the line by varying the length of two segments of the line. The locations range from 0 to $100 \%$ of the line length. In this situation, the apparent impedance seen by the relay A is shown in Figure 8. It is clear that the apparent impedance without TCSC increases linearly by the fault location in the line. In the situation with TCSC, the apparent impedance seen by the relay A changes nonlinearly by the fault location in the line. With TCSC at the firing angle of $180^{\circ}, 155^{\circ}$, and $150^{\circ}$ an impedance resonance point occurs between the reactance of TCSC and the impedance of line. The point is the lowest impedance in its characteristic as shown in Figure 8 . Therefore, the firing angle of TCSC has an influence on the apparent impedance seen by the relay $\mathrm{A}$.

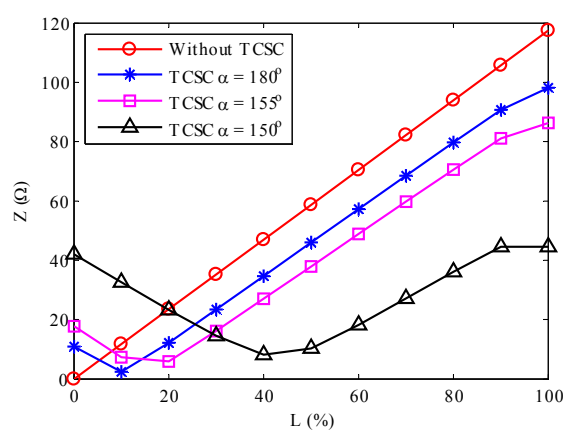

Fig. 8. Apparent impedance according to fault location.

In this work, high resistance faults are considered in order to investigate the influence of TCSC on apparent impedance seen by the distance relay A. The fault resistances are changed in the range of 0 to $50 \Omega$. Because of the fault resistance, the apparent impedance will be changed as shown in Figure 9. The curves in Figure 9, including cases: without TCSC, with TCSC at the firing angle of $180^{\circ}, 155^{\circ}$, and $150^{\circ}$ are shown. This states that the modeling of the system can be used to analyze the impact of TCSC and the fault resistance on apparent impedance seen by the relay A comprehensively.

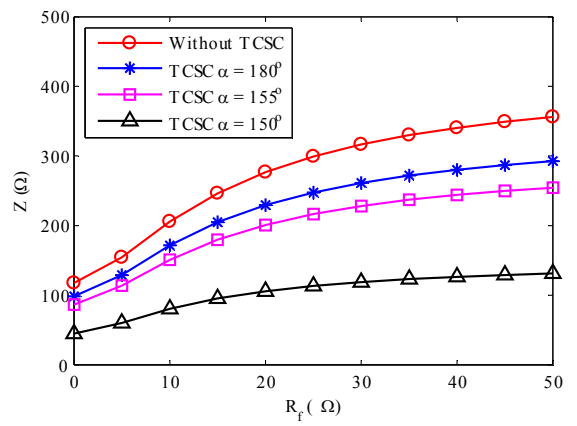

Fig. 9. Apparent impedance according to fault resistance.

The simulation results shown in Figure 10 are the hybrid of fault location and resistance. The fault locations range from 0 to $100 \%$ of the line length and the fault resistances are set at 0 , 10,20 , and $30 \Omega$. All faults simulated in this work are the Ph-G fault that occurs at 0.2 seconds. The apparent impedance $(Z)$ seen by the relay $\mathrm{A}$ is separated to the resistance $(R)$ and reactance $(X)$. They are shown in impedance plane in which $\mathrm{x}$ - axis is the resistance and y-axis is the reactance. In addition, the Mho characteristic of zone 1 is also plotted in order to identify the faults inside or outside zone 1.

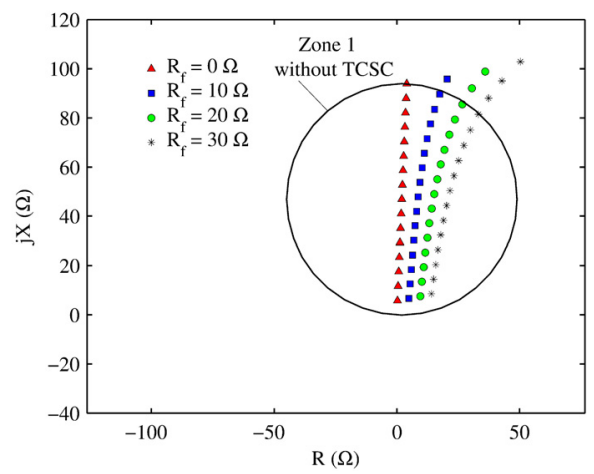

(a) Without TCSC

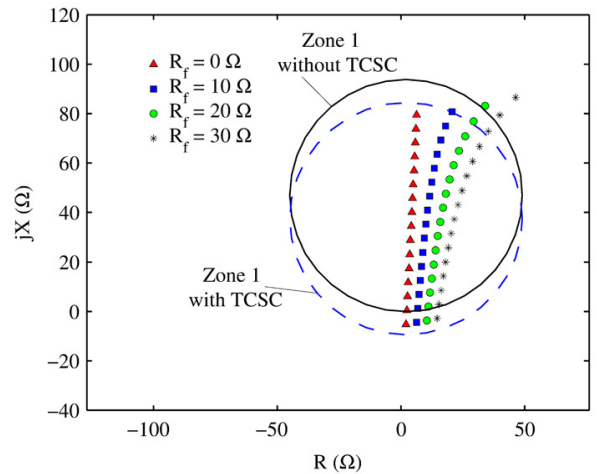

(b) TCSC $\alpha=180^{\circ}$

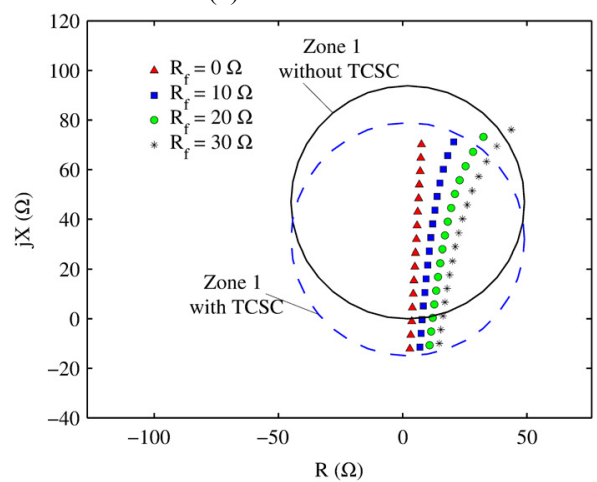

(c) $\operatorname{TCSC} \alpha=155^{\circ}$

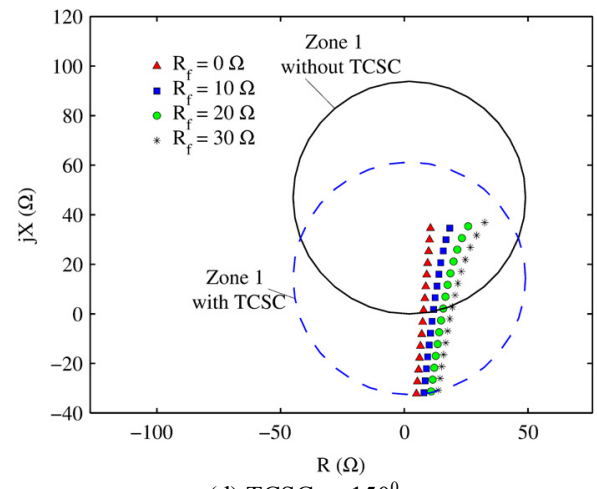

(d) $\operatorname{TCSC} \alpha=150^{\circ}$

Fig. 10. Mho characteristic of distance relay according to the firing angle 
The results in Figure 10 are for the cases without TCSC and with TCSC with firing angle at $180^{\circ}, 155^{\circ}$, and $150^{\circ}$. Simulation results show that the firing angle of TCSC has an impact on the distance relay A. This can make the relay unable to operate correctly when the fault occurs because the point is outside of the zone 1 . Therefore, the zone 1 is modified according to the firing angle of TCSC to identify the fault correctly (Figures 10(b)-(d)).

\section{CONCLUSION}

Modeling for development of simulation tool of impact of TCSC on apparent impedance seen by distance protection relays has been proposed in this study. The algorithm for determining capacitance and inductance parameters of TCSC has been developed comprehensively and the method for calculating resistance and reactance seen by distance relay has been proposed. A 3-phase, $500 \mathrm{kV}$ transmission line in presence of TCSC which affects relay settings for fault conditions has been modeled and simulated in Matlab/Simulink. In the model, $\mathrm{Ph}-\mathrm{G}$ faults are applied in the line at different locations in order to evaluate the impact of TCSC on distance relays. Simulation results show that the firing angle of TCSC has an impact on apparent impedance seen by distance protection relays. Therefore, it is necessary for distance relay to adjust new settings in its Mho characteristics and adapt to system conditions according to the firing angle of TCSC.

\section{APPENDIX}

\author{
- The parameters of each source are: \\ Voltage at both sources: $500 \mathrm{kV}$ line-line rms, $50 \mathrm{~Hz}$ \\ Thévenin's resistance and inductance of: \\ Source A: $R=0.8929 \Omega, L=16.58 \mathrm{mH}$ \\ Source B: $R=0.8929 \Omega, L=16.58 \mathrm{mH}$ \\ Phase angle between two ends: $10^{\circ}$ \\ - The parameters of the line are: \\ Length of line: $400 \mathrm{~km}$ \\ Positive-sequence parameters: \\ Positive-sequence resistance: $r_{l}=0.01273 \Omega / \mathrm{km}$ \\ Positive-sequence inductance: $L_{l}=0.9337 \mathrm{mH} / \mathrm{km}$ \\ Positive-sequence capacitance: $C_{l}=12.74 \mathrm{nF} / \mathrm{km}$ \\ Zero-sequence parameters: \\ Zero-sequence resistance: $r_{0}=0.3864 \Omega / \mathrm{km}$ \\ Zero-sequence inductance: $L_{0}=4.1264 \mathrm{mH} / \mathrm{km}$ \\ Zero-sequence capacitance: $C_{0}=7.751 \mathrm{nF} / \mathrm{km}$ \\ - The parameters of TCSC: \\ Capacitance: $C=0.136 \mathrm{mF}$ \\ Inductance: $L=10 \mathrm{mH}$
}

\section{ACKNOWLEDGMENT}

This work was supported by Quy Nhon University, code number of project: T2018.569.18.

\section{REFERENCES}

[1] E. Acha, C. R. Fuerte-Esquivel, H. Ambriz-Perez, C. Angeles-Camacho, FACTS Modelling and Simulation in Power Networks, Wiley, 2004

[2] S. Jamhoria, L. Srivastava, "Applications of thyristor controlled series compensator in power system: an overview", 2014 international conference on power signals control and computations (EPSCICON), Thrissur, India, January 6-11, 2014

[3] S. Biswas, P. K. Nayak, "State-of-the-art on the protection of FACTS compensated high-voltage transmission lines: a review", High Voltage, Vol. 3, No. 1, pp. 21-30, 2018

[4] M. Zellagui, A. Chaghi, "Impact of TCSC on Measured Impedance by MHO Distance Relay on $400 \mathrm{kV}$ Algerian Transmission Line in
Presence of Phase to Earth Fault", Journal of Electrical Systems, Vol. 8, No. 3, pp. 273-291, 2012

[5] M. Zellagui, A. Chaghi, "Impact of Apparent Reactance Injected by TCSR on Distance Relay in Presence Phase to Earth Fault", Power Engineering and Electrical Engineering, Vol. 11, No. 3, pp. 156-168, 2013

[6] E. Reyes-Archundia, J. L. Guardado, E. L. Morenogiytia, J. A. Gutierrez-Gnecchi, F. Martinez-Cardenas, "Fault Detection and Localization in Transmission Lines with a Static Synchronous Series Compensator", Advances in Electrical and Computer Engineering, Vol. 15, No. 3, pp. 17-22, 2015

[7] P. Jena, A. K. Pradhan, "Directional Relaying in the Presence of a Thyristor-Controlled Series Capacitor", IEEE Transactions on Power Delivery, Vol. 28, No. 2, pp. 628-636, 2013

[8] M. Khederzadeh, T. S. Sidhu, "Impact of TCSC on the protection of transmission lines", IEEE Transactions on Power Delivery, Vol. 21, No. 1, pp. 80-87, 2006

[9] T. S. Sidhu, M. Khederzadeh, "TCSC impact on communication-aided distance-protection schemes and its mitigation", IEE Proceedings Generation, Transmission and Distribution, Vol. 152, No. 5, pp. 714728,2005

[10] S. M. Hashemi, M. T. Hagh, H. Seyedi, "High-speed relaying scheme for protection of transmission lines in the presence of thyristorcontrolled series capacitor", IET Generation, Transmission \& Distribution, Vol. 8, No. 12, pp. 2083-209, 2014

[11] A. Maori, M. Tripathy, H. O. Gupta, "An advance compensated Mho relay for protection of TCSC transmission line", 6th IEEE Power India International Conference (PIICON), Delhi, India, December 5-7, 2014

[12] K. K. Sen, M. L. Sen, Introduction to FACTS Controllers: Theory, Modeling and Applications, New Jersey: John Wiley \& Sons, 2009

[13] S. Bruno, G. D. Carne, M. L. Scala, "Transmission grid control through TCSC dynamic series compensation", IEEE Transactions on Power Systems, Vol. 31, No. 4, pp. 3202-3211, 2016

[14] IEEE Standard 1534, IEEE Recommended Practice for Specifying Thyristor Controlled Series Capacitor, New York: IEEE Power and Energy Society, 2009

[15] S. Meikandasivam, R. K. Nema, S. K. Jain, "Selection of TCSC parameters: Capacitor and inductor", India International Conference on Power Electronics, New Delhi, India, January 28-30, 2011

[16] B. H. Li, Q. H. Wu, D. R. Turner, X. Zhou, "Modelling of TCSC dynamics for control and analysis of power system stability", International Journal of Electrical Power \& Energy Systems, Vol. 22, No. 1, pp. 43-49, 2000 